\title{
Kekerasan dan Kritik Sosial dalam Pandangan Islam
}

\author{
Amir Mu'allim
}

\section{Pendahuluan}

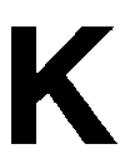

emajemukan masyarakat biasanya membawa pola hidup yang beragam dan tidak mustahil dalam hidup kesehariannya akan menimbulkan berbagai persoalan atau bahkan mengarah kepada konflik. Status pekerjaan, tingkat pendidikan, politik, idologi dan agama adalah berbagai faktor yang menjadi pemicu konflik dalam kehidupan sosial masyarakat.

- Berbagai kasus yang terjadi akhir-akhir ini seperti peristiwa Tasikmalaya, Pontianak, Rengas Dengklok bermula dari faktor yang dihubungkan dengan kepentingan tertentu; di samping masalah-masalah lain yang berhubungan dengan konflik internal seperti perkosaan, pembunuhan, perampokan dan hal-hal lain yang berkaitan dengan kesenjangan sosial.

Sebagai ilustrasi adalah peristiwa klasik yang terjadi pada masa Nabi Muhammad. Pada waktu itu orang Yahudi yang kafir dengan Muharimad, padahal mereka tadinya menantikan kedatangan $\mathrm{Nabi}$. Hal ini karena orang-orang Yahudi menginginkan agar Nabi yang akan datang itu diutus dari golongan mereka untuk mengangkat derajat dan melanjutkan kekuasaan mereka terhadap manusia seluruhnya. Tetapi agama Islam dibawa oleh seorang Nabi bangsa Arab dan bukan dari dari bangsa
Yahudi (A. Syalabi, 1990:131). Persoalan ini akhirnya mewujudkan adanya kompetensi kepentingan yang berakibat konflik.

Menyimak prinsip dasar tentang problematika kerawanan sosial seperti yang digariskan dalam Islam memberi kesan yang beragam, artinya konsep-konsep dasar yang ditawarkan dalam Al Qur'an dan as Sunnah tidak menentukan satu cara, akan tetapi diberikan berbagai alternatif tergantung dari jenis permasalahannya.

$\mathrm{Hal}$ ini karena ayat-ayat Al Qur'an yang diturunkan kepad Nabi Muhammad mempunyai latar belakang historis yang adakalanya berdimensi sosio kultural seperti turunnya ayat yang mengharamkan tentang khamar yang tidak secara sekaligus memvonis dengan kalimat haram, tetapi melalui bahasa yang bertahap. $\mathrm{Hal}$ ini oleh sebagian orang dikatakan sebagai metode dalam merubah tatanan masyarakat Arab pada waktu itu yang sudah demikian kentalnya dengan tradisi minuman keras.

Dalam hal lain, kadangkala Al Qur'an menggunakan bahasa yang langsung terutama yang menyangkut keamanan masyarakat dan kemaslahatan umat, seperti masalah pencurian, pembunuhan dan lainlain.

Kesulitan dalam menterjemahkan bahasa Al Qur'an dan Al Hadis apabila berhadapan dengan orang apalagi kalau sudah menyangkut masalah kepentingan baik 
kepentingan individu, kelompok, idologi dan kepentingan-kepentingan lain. Sehingga ada istilah masalah yang jelas dapat dikaburkan dan masalah yang samar-samar dapat dibuat jelas. Melihat fakta-fakta sejarah dan didukung dengan tuntutan kritis masyarakat, maka perlu dikaji tentang bagaimana Islam menterjemahkan persoalan-persoalan kehidupan masyarakat terutama yang menyangkut aspek kekerasan dan kritik sosial.

Tulisan ini mencoba memaparkan suatu konsep tentang kekerasan dan kritik sosial dalam pandangan Islam sebagai telaah banding tentang konsep kekerasan yang disampaikan oleh beberapa komentator.

\section{Kekerasan antara Sikap dan Metode}

Persoalan kekerasan adakalanya di hubungkan dengan sikap seseorang yang mengandung arti sifat, kegiatan, kekuasaan (WJS Poerwadarminta, 1983:458) dan adakalanya dihubungkan dengan metode yang biasa diterapkan dalam berdakwah. Kedua pengertian ini dalam Islam mempunyai makna yang saling berhubungan, karena kekerasan juga mempunyai makna metode menyampaikan sikapnya sebagai alternatif menyelesaikan masalah. Hanya, saja orang sering mengidentifikasi kekerasan dengan perilaku yang negatif.

Sebagai bandingan dapat dikemukan komentar Muhammad Nuh Nabhani yang menggambarkan kekerasan sebagai kristaliasi dari berbagai persoalan. Jadi kalau digambarkan dengan ilmu teknik bahwa setiap persoalan itu bisa digambarkan sebagai satu vektor, satu persoalan satu vektor lagi, satu persoalan satu vektor lagi dan seterusnya. Dan kekerasan yang berkembang dalam masyarakat itu multiple persoalan. Sehingga pada vektor-vektor itu nantinya membentuk vektor baru yang lebih besar resultannya, dan gayanya juga lebih besar. Itulah kekerasan. Karena persoalan di masyarakat itu mengkristal, maka semakin keras dan semakin kasar. Terapinya adalah hakekat dari persoalannya itu harus diselesaikan, atau dilunakkan. Sebenarnya jiwa manusia itu halus. Tapi karena terkontaminasi persoalan-persoalan yang tidak menghiraukan moral, maka manusia akan jadi lebih keras, lebih beringas. Dan ciri dari orang yang beriman mestinya halus, lemah lembut. Sebaliknya ciri dari orang yang tidak memiliki tatanan nilai yang benar, akan menjadi kasar, beringas dan sebagainya (Muhammad Nuh Nabhani, 1997:97).

Ungkapan tersebut dalam hal tertentu dapat dibenarkan tetapi dalam hal lain konsep semacam itu tidak pas, karena ada masalah-masalah tertentu yang tidak akan selesai apabila dihadapi dengan cara lunak, lembut halus terutama masalah yang menyangkut kepentingan keselamatan agama, menghadapi orang-orang kafir, kriminalitas dan sebagainya. $\mathrm{Hal}$ ini dapat dilihat dalam al Qur'an yang menyatakan tentang sikap tegas asyiddau alal kuffar terhadap orangorang kafir yang dalam istilah kamus lafal "asyidda" sering diterjemahkan dengan yang keras (Mahmud Yunus, 1989:508). Dengan demikian istilah kekerasan atau yang menginduk pada kalimat keras tidak mesti berkonotasi jelek, tergantung kepada konteksnya.

Dalam konteks perilaku kekerasan dapat mengandung arti jelek seperti penganiayaan, perkosaan, pembunuhan yang dalam klasifikasinya dapat digolongkan sebagai kekerasan internal individu. Dan juga seperti peristiwa penyerangan, perang tanding, tawuran pelajar yang digolongkan sebagai kekerasan kelompok atau seperti penganiayaan buruh oleh majikan (perusahaan), penggusuran tanah tanpa ganti rugi yang memadai, penyiksaan dalam kepolisian, penindasan politik oleh satu negara 
besar terhadap negara kecil, peperangan rasialisme dan lain sebagainya, yang dikategorikan sebagai kekerasan struktural.

Dalam konteks lain kekerasan dapat berarti sebaliknya, seperti halnya dalam konteks menyampaikan kebenaran atau meluruskan perilaku mungkar dan lain sebagainya seperti digambarkan dalam Al Qur'an bahwa sebagian besar dari orangorang alim Yahudi dan rahib-rahib Nasrani benar-benar memakan harta orang dengan jalan yang bathil, dan mereka menghalanghalangi (manusia) dari jalan Allah. Dan orang-orang yang menyimpan emas dan perak dan tidak menafkahkannya di jalan Allah, maka beritahukanlah kepada mereka (bahwa mereka akan mendapat) siksa yang pedih (at Taubah:34).

Hadis Nabi yang diriwayatkan oleh Muslim menyatakan bahwa siapa diantara kamu melihat mungkar harus merubah dengan tangannya, bila tidak dapat maka dengan mulut (lisannya), apabila tidak dapat maka dengan hatinya, dan ini selemahlemah iman (Salim Bahreisy, 1982:197198). Dalam keterangan hadis ini dijelaskan bahwa membasmi mungkar itu dengan kekerasan, kekuatan tangan atau lidah, atau kalau dikhawatirkan akan lebih besar bahayanya maka membenci dalam hati.

Hadis lain yang hampir senada mengatakan bahwa tiada seorang Nabi yang diutus sebelumku melainkan mempunyai sahabat-sahabat yang setia yang mengikuti benar-benar tuntunan ajarannya, kemudian timbul di belakang mereka turunan yang hanya banyak bicara dan tidak suka berbuat dan mengerjakan apa-apa yang tidak diperintahkan, maka siapa yang memerangi mereka dengan kekuatan tangannya, ia mukmin dan siapa yang menantang mereka dengan lidahnya juga mukmin dan siapa yang membenci mereka dengan hatinya iapun mukmin. Selain dari itu tidak ada lagi iman walau sebesar biji sawi (Salim
Bahreisy, 1983:198, HR. Muslim).

Dalil-dalil tersebut memberi gambaran tentang cara untuk menjinakkan seseorang dari kecenderungan mereka berbuat mungkar yang kalau digunakan dengan bahasabahasa yang lunak atau cara-cara yang halus tidak akan membuat kejenuhan mereka untuk berbuat mungkar. Hal ini dalam bahasa Al Qur'an atau Hadis digunakan kalimat yang beragam tidak selalu berkonotasi jelek terutama yang berkaitan dengan prinsip-prinsip metodologis artinya ada persoalan-persoalan tertentu yang perlu ada trik-trik khusus yang harus dibahasakan dengan keras agar menjadi perhatian yang serius. Sebab kalau ada pelanggaran yang mempunyai bobot tinggi kemudian dihadapi dengan bahasa-bahasa atau cara-cara yang halus akan dikesampingkan begitu saja. Oleh karena itu dalam kaitan ini Allah SWT memberikan teguran kepada Nabi Mủhammad SAW yang memperlakukan tawanan perang dengan cara tebusan seperti yang ditawarkan Abu Bakar dan menolak usul Umar agar tawanan perang itu dibunuh saja sehingga turunlah ayat 67 surat Al Anfal yang mengatakan bahwa "Tidak patut bagi seorarng Nabi mempunyai tawanan sebelum dia dapat melumpuhkan musuhnya di muka bumi. Kamu menghendaki harta benda duniawiyah sedangkan Allah menghendaki (pahala) akhirat (untukmu). Dan Allah Maha Perkasa lagi Maha Bijaksana".

Secara spesifik seorang muslim dibolehkan atau dianjurkan untuk bersikap keras terhadap orang-orang kafir seperti disebutkan dalam surat $\mathrm{Al}$ Fath ayat 29 yang menyatakan bahwa "Muhammad itu adalah utusan Allah dan orang-orang yang bersama dengan dia adalah keras terhadap orang-orang kafir tetapi berkasih sayang sesama mereka ..."

Dengan kalimat lain maka tidak salah sikap keras atau kekerasan itu digunakan 
dalam hal-hal yang secara Syar'i memang dibolehkan, dalam pengertian tidak sembarangan persoalan mungkar harus dihadapi dengan kekerasan.

\section{Kritis dan Kritik Sosial}

Ada ungkapan menarik yang disampaikan oleh B. J. Habibie bahwa hanya surga yang tidak ada kesenjangan sosial (Kedaulatan Rakyat, 20 Februari 1997:16). Ungkapan Habibie tersebut menegaskan bahwa selama orang hidup di alam dunia tentu berhadapan dan mengalami kesenjangan sosial. Hanya yang perlu diupayakan adalah kesenjangan sosial yang tidak bisa dihindari di muka bumi ini menjadi sekecil mungkin. Penegasan Habibie tersebut menanggapi tentang kekerasan yang menurutnya bahwa kekerasan itu bukan disebabkan budaya kita (maksudnya bangsa Indonesia), karena budaya kita tidak mengenal bakar membakar seperti itu. Selain itu bukan akibat SARA, karena SARA itu bukan baru kemarin. Kita juga mengenal SARA berbeda suku, agama, ras itu puluhan, ratusan tahun.

Mencermati tentang kesenjangan sosial tidak lepas dari persoalan kritis dan kritik sosial. Kalau kita mundur jauh ke belakang maka kita mengenal peristiwa pembunuhan antara Qabil dan Habil anak Nabi Adam AS yang berawal dari sikap kritis terhadap keputusan orang tuanya karena Qabil dikawinkan dengan pasangan dampitnya, yang tidak sesuai dengan selera Qabil dan berakhir dengan konflik.

Jadi tidak'salah kalau Habibie mengatakan bahwa kesenjangan sosial sudah terjadi ratusan tahun atau bahkan ribuan tahun yang antara lain dilatarbelakangi oleh sikap kritis dalam menanggapi kehidupan sosial.

Dalam Islam sikap kritis merupakan sikap yang terpuji bahwa sebagian ayat membahasakan dengan kalimat perintah. Seperti tersebut dalam ayat 6 surat al Hujarat yang menyatakan bahwa "Hai orangorang yang beriman jika datang kepadamu orang fasik membawa suatu berita, maka periksalah dengan teliti, agar kamu tidak menimpakan suatu musibah kepada suatu kaum tanpa mengetahui keadaannya yang menyebabkan kamu menyesal atas perbuatanmu itu". Ayat-ayat lain yang berujung pada kalimat afalaa ta'qilun, afalaa tatafakkarun, laayatil liulil albaab, pada hakekatnya mengandung makna kritis yang pada ujungnya dapat digunakan sebagai alat untuk menemukan kebenaran yang hakiki yang berakar pada wahyu Allah dan petunjuk sunnah Rasul dan bukan sebaliknya menjauhkan dari kebenaran Qur’ani.

Oleh karena itu ayat 6 surat al Hujarat diawali dengan kalimat yaa ayyuhal ladziina aamanuu, agar tidak lepas dari kendali ilahiyah. Apabila kita menggolongkan tipologi manusia dalam menangkap suatu $\cdot k e-$ hendak dapat diklasifikasikan kepada 4 golongan, yaitu: 1) jahil; 2) muqollid; 3) muttabi; dan 4) mujtahid. Dan sikap kritis menempati urutan nomor 4 yaitu mujtahid. Walaupun hal ini hanya sekedar ilustrasi karena tidak otomatis orang yang kritis adalah orang mujtahid, karena seorang yang digolongkan mujtahid harus memenuhi persyaratan tertentu. Hanya saja pada prinsipnya seorang mujtahid harus mempunyai sikap kritis untuk mencari mana yang keliru dan mana yang paling benar.

Berkaitan dengan masalah kritis, maka biasanya mengandung makna kritik terutama yang berkaitan dengan kehidupan sosial. Karena kalau dikaji secara mendalam maka'muatan ayat-ayat al Quran berisikan kritik terhadap kehidupan masyarakat. Selama 23 tahun Nabi Muhammad SAW diutus menjadi rasul tidak lain misinya adalah memberikan kritikan terhadap persoalan-persoalan sosial manusia baik yang 
terjadi pada masyarakat Arab di Mekkah maupun di Madinah yang dari kritikan itu terbangun kondisi yang konstruktif yang akhirnya menjadi kiblat bagi kehidupan manusia seluruhnya. Hanya saja alat yang digunakan untuk mengkritik adalah alat yang sudah mapan dan yakin akan kebenarannya.

Oleh karena itu apabila ada kritik yang isinya memang sesuai dengan prinsipprinsip dasar Qur'ani, maka tidak perlu ada istilah akan dipertimbangkan dulu atau istilah-istilah lain yang meremehkan isi kritikan tersebut. Dan sebaliknya kalau kritikan itu tidak sesuai dengan prinsipprinsip dasar Qur'ani, maka siapapun yang mengkritik harus ditolak. Sudah barang tentu istilah Qur'ani harus ditangkap maknanya tidak sekedar apa adanya karena muatan Al Qur'an tidak hanya bisa dilihat dari arti yang tersurat (literal meaning) tetapi juga arti yang tersirat (figurative meaning). Hal ini dapat kita lihat contoh kisah Musa dengan Khidhir yang akhirnya diabadikan dalam al Quran. Secara tersurat pada waktu Khidhir melobangi perahu dan membunuh seorang anak, maka orang akan mengatakan bahwa hal itu adalah tidak baik. Tetapi dalam contoh peristiwa ini menggambarkan tentang makna dibalik peristiwa melobangi perahu dan membunuh seorang anak ada kebaikan-kebaikan yang tidak secara langsung dapat dirasakan.

$\mathrm{Hal}$ ini juga dicontohkan Nabi Muhammad SAW pada waktu ditanya Siti Aisyah RA yaitu pernahkah terjadi padamu suatu hari yang labih berat daripada penderitaanmu ketika perang Uhud? Jawab Nabi SAW saya telah menderita beberapa kejadian dari kaummu, dan yang terberat yaitu hari aqabah ketika saya berpropaganda kepada Ibnu Abd Jalail bin Abd Kulal yang mana tidak seorangpun dari mereka yang menyambut ajaranku, maka saya kembali dengan hati yang kesal, sehingga seolah- olah saya berjalan dengan tidak sadar, hanya ketika sampai di Qarnits tsa'alib, di situ baru saya sadar dan mengangkat kepalaku ke langit di mana saya melihat awan di atasku, tiba-tiba Malaikat Jibril memanggil saya sambil berkata: Allah telah mendengar jawaban kaummu dan kini telah mengutus malaikat penjaga bukit untuk menurut segala perintahmu. Kemudian terdengar suara malaikat penjaga bukit memberi salam sambil berkata: Ya Muhammad, Allah telah mendengar jawaban kaummu kepadamu, dan malaikat penjaga bukit diperintahkan Allah menurut segala kehendakmu, maka perintahlah saya sesukamu. Kalau kau suka saya dapat merobohkan dua bukit yang terbesar di daerah kota Mekkah (bukit al Akhsyabain). Jawab Nabi SAW: Tetapi saya masih mengharap semoga Allah mengeluarkan dari turunan mereka orang-orang yang beribadat kepada Allah dan tidak mensekutukan padaNya (Salim Bahreisy, 1983:519-520, HR. Bukhori Muslim).

Hadis tersebut memberikan ilustrasi tentang cara menangkap makna suatu peristiwa yang tidak boleh hanya dipandang sebelah mata. Dan di sisi lain Hadis tersebut memberikan cerminan tentang diperlukannya sifat kemapanan dan kemandirian dalam sikap pengambilan keputusan, artinya apapun kritikan yang dilontarkan maka hal-hal yang sudah dimantapkan dalam dirinya tidak dirobah begitu saja.

Suatu ungkapan yang menarik untuk direnungkan adalah kata-kata Imam Ghazali yang mengatakan bahwa apabila kita melihat bintang maka dalam perhitungan kasarnya bahwa besarnya bintang itu sama besarnya dengan uang logam dinar. Kemudian setelah melalui bukti-bukti ilmu bangun (geometri) ternyata bintang itu lebih besar dari pada bumi dalam ukurannya (al Gahazali, tth:29). 
Kata-kata Ghazali tersebut memberikan pengertian bahwa menilai sesuatu jangan hanya dipandang secara spontan dan hanya satu sisi tetapi juga sisi-sisi lain yang lebih mendukung kebenarannya juga harus dilihat. Dengan demikian kita dituntut untuk selalu jeli dalam menangkap kritik dan juga menyampaikan kritik sehingga tidak berakibat fatal. Karena kritik dalam tatanan kehidupan manusia ada bermacam-macam, ada kritik individu (perorangan), kritik idiologi, kritik pemerintah, kritik jabatan dan lain sebagainya yang kalau tidak hati-hati akan terjadi paradoksal yang akhirnya menjurus kepada kesenjangan sosial.

Satu contoh yang dilakukan Nabi SAW bahwa beliau tidak pernah menuntut balas hal-hal yang berkenaan dengan pribadinya sendiri kecuali yang dilanggar. yang diharamkan oleh Allah, maka beliau menuntut balas karena Allah (Salim Bahreisy, 1982: 517).

Arti dari hadis ini adalah kita tidak perlu kaget dengan kritikan-kritikan yang sifatnya mengarah kepada perbaikan pribadi bahkan sebaliknya bahwa kritikan itu adalah dapat berguna. Oleh karena itu prinsip dasar dari pada persoalan kritik adalah fastabiqul khairat (berlomba-lomba menuju kebaikan).

\section{Kesimpulan}

Kekerasan dalam prakteknya tidak mesti berarti jelek, bahwa dalam beberapa hal kekerasaan itu perlu digunakan terutama dalam masalah-masalah yang tujuannya untuk memberantas kemungkaran dan tidak ada alternatif lain.

Sikap kritis dalam menangkap permasalahan adalah sifat yang terpuji selama kekritisannya didasarkan atas burhan/bukti yang akurat yang dijiwai dengan kebenarankebenaran ilahiyah, sehingga dapat meminimalisasi rapuhnya isi kritikan.

Kritik sebagai alat untuk meluruskan keadaan adalah kewajiban bagi setiap orang dan dalam menerima kritik harus dilepaskan baju-baju kehormatan, sehingga tidak ada istilah kebal terhadap kritik.

\section{Daftar Pustaka}

Al Ghazali, Abi Hamid Muhammad bin Muhammad bin Muhammad (tth), al Munqid Minadholal, al Maktabah as Sya'biyah, Beirut, Libanon.

An Nawawi, Imam Abu Zakariya Yahya bin Syaraf, terjemahan Salim Bahreisy (1983), Riyadus Shalihin, Al Ma'arif, Bandung.

A. Syalabi (1990), Sejarah dan Kebudayaan Islam, Pustaka al Husna, Jakarta.

Depertemen Agama RI (1993), Al Qur'an dan Terjemahnya, C.V. Kathoda, Jakarta.

Habibie, H. J., Hanya Surga yang Tak Ada Kesenjangan Sosial, Kedaulatan Rakyat, 20 Februari 1997.

Nabhaani, Muhammad Nuh (1997), Berawal dari Jiwa yang Kacau, al Muslimun, Nomor 322, Tahun XXVII (43). 